\title{
Novel Reduced Parts Online Uninterruptible Power Supply
}

\author{
Bahram Ashrafi and Mehdi Niroomand \\ Department of Electrical Engineering, University of Isfahan (UI), Isfahan 81746-73441, Iran \\ Correspondence should be addressed to Mehdi Niroomand, mehdi_niroomand@eng.ui.ac.ir
}

Received 18 May 2012; Revised 2 October 2012; Accepted 12 October 2012

Academic Editor: Hadi Y. Kanaan

Copyright ( 2012 B. Ashrafi and M. Niroomand. This is an open access article distributed under the Creative Commons Attribution License, which permits unrestricted use, distribution, and reproduction in any medium, provided the original work is properly cited.

\begin{abstract}
This paper presents design consideration and performance analysis of novel reduced parts online three-phase uninterruptible power supply (UPS) system. The proposed UPS system is based on reduced switch count dual bridge matrix converter. It employs only six power switches and results in reducing the cost of the system compared to conventional online UPS topologies, while achieving excellent performance. The performance of the proposed system is evaluated through simulation in terms of input/output waveforms quality and shows the viability of topology.
\end{abstract}

\section{Introduction}

Protecting sensitive loads like medical facilities, life supporting systems, data centers, telecommunication systems, and industrial processing systems are the main purpose of implementing uninterruptible power supplies (UPSs system) [1]. UPS system has to provide distortion free, high quality waveforms in order to ensure the reliable operation of the load, regardless of quality of the AC power source [2].

Different types of UPS systems are developed since the advent of UPS concept. Among these types, the online UPS is the most common type for low to medium power applications due to its superior performance such as high tolerance to the input voltage variation and precise regulation of the output voltage [3]. However, conventional online UPS topology employs big number of switches and as a consequence, suffers from high cost, which stops it from adopting in some cost sensitive applications like personal computers. So the idea of developing different topologies to reduce the cost of UPS systems attracts researcher's attention [4].

In general, the cost reduction is achieved by developing topologies in order to [5]

(i) reduce the number of power switches,

(ii) replace power switches with diodes, because diodes are cheaper than active power switches.
Employing the mentioned methods would further reduce the cost by eliminating the circuitry for driving power switches and simplifying the control circuit:

(i) lowering the voltage stress across power switches,

(ii) eliminating passive components like transformers, capacitors, and inductors.

Removing bulky passive elements and lowering the number of power switches would bring some advantages like greater compactness and higher reliability.

This paper present the design and performance analysis of a new online three-phase UPS system based on dual bridge matrix converter topology. The concept of reducing the number of switches is applied by using 9 switch dual bridge matrix converter. Further switch reduction is obtained by using capacitor midpoint connection (two series capacitors in dc-link) which leads to 6 switch topology.

The rest of the paper is organized as follows. In the first part, brief introduction to online UPS is presented and three different operation modes are discussed. In the next part the applied topology is introduced. It starts with dual bridge matrix converter and description of the switch reduction procedure from 24 to 9 and continues with capacitor midpoint connection concept, which further reduced the switches count to 6 . Finally, simulation results are presented to demonstrate the feasibility of the proposed method. 


\section{Online Uninterruptible Power Supply (UPS)}

Double conversion online UPS is depicted in Figure 1, based on IEC standard 62040-3.

As shown in Figure 1, this topology consists of rectifier, battery management set, battery pack, inverter, and static switches (bypass) [6]. As the term "Double Conversion" suggests, an online UPS converts power twice. At first, AC input voltage with all the distractions is converted into DC voltage. For stabilizing the DC voltage, a capacitor is used at the end of the rectification stage.

Second, DC voltage is converted back to regulated AC voltage to supply the load with high quality, uninterrupted power. The output AC voltage can even manage to have different frequency than input voltage, which is not possible with line-interactive UPS. When the AC input is available (normal mode of operation), described double conversion process would occur. In online UPS, inverter is rated at 100\% of the load in order to supply the load, and rectifier power rating is set to meet the $100 \%$ of the power demanded by the load and power needed to charge the battery bank [2].

When AC input is outside of the desired range, the UPS is disconnected from AC source and the power is drawn from the battery, so the output is not affected. The transition time for switching from power source to the battery set is several milliseconds, and the capacitor in the dc-link supplies the load during transition time. So even there is a short interruption in power flow, the output voltage would remain continuous.

In brief, online UPS has 3 different operating modes: normal mode, stored energy mode, and bypass mode $[1,2]$.

2.1. Normal Mode of Operation. In this mode, input AC source supplies the load through double conversion process, which is AC-DC via front-end rectifier and DC-AC via backend inverter. The dc-link voltage is also used to charge the batteries. In comparison with line-interactive UPS, online topology has higher power rating and results in higher cost. The efficiency of online UPS is usually lower than lineinteractive one, so it consumes more power and produces more heat, which results in higher utility cost and additional cooling expense.

2.2. Stored-Energy Mode of Operation. In this mode the UPS is disconnected from AC input source, due to the distraction of the voltage source. The continuity of power flow is maintained by batteries and inverter. The duration of this mode depends on availability of AC line and batteries backup time.

2.3. Bypass Mode of Operation. In bypass mode, load is directly connected and fed by AC input source. It should be considered that the source frequency and load frequency should be equal in order to make the direct connection between source and load possible.

UPS operates in this mode when there is an internal malfunction or in case of maintenance.

The main advantages of online UPS are as follows $[3,4]$. (i) High tolerance against the input voltage variations.

(ii) Regulation of the output voltage.

(iii) Controllable output frequency. It can perform frequency conversion (e.g., $50 \mathrm{~Hz}$ to $60 \mathrm{~Hz}$ ).

The main disadvantages of this topology are low power factor, low efficiency, and high THD.

The rectification stage causes distortion to the input current. So an extra power factor correction stage is needed, which leads to higher cost:

(i) higher power losses compared to line-interactive UPS,

(ii) shorter life span compared to other topologies due to higher temperature.

Double conversion online UPS, with all mentioned drawbacks, is the most preferred topology in performance, power conditioning, and load protection. There is a large diversity in online UPS topologies to fulfill different tasks in different kind of applications, in range of few KVA to several MVA.

\section{Matrix Converter}

The matrix converter (Figure 2), first introduced in 1980, is an ac to ac force commutated converter structure. It is able to provide simultaneous voltage and frequency transformation [6].

Matrix converter employs four-quadrant switches, and by choosing proper modulation technique, it makes bidirectional power flow from source to load possible. So it inherently can regenerate energy back to source. Matrix converter does not employ any electrolytic capacitors or any other passive elements in dc-link, so it shows high reliability. These features make matrix converter suitable topology in applications like AC drives or power supplies $[7,8]$.

Recent trends to make higher quality, more efficient power supplies, caused renowned attention and extensive research work on matrix converter due to its superior characteristics like [5]:

(i) sinusoidal input and output waveforms,

(ii) adjustable power factor,

(iii) bidirectional power flow,

(iv) compact design (no bulky energy storage is needed),

(v) adjustable frequency.

In general, there are two major derivations in matrix converter topology. First one is conventional matrix converter in Figure 2, and the second one is dual bridge [911] approach which has "dc link" [5] and is depicted in Figure 3. Dual bridge matrix converter also called "indirect matrix converter" in the literature [11-13]. 


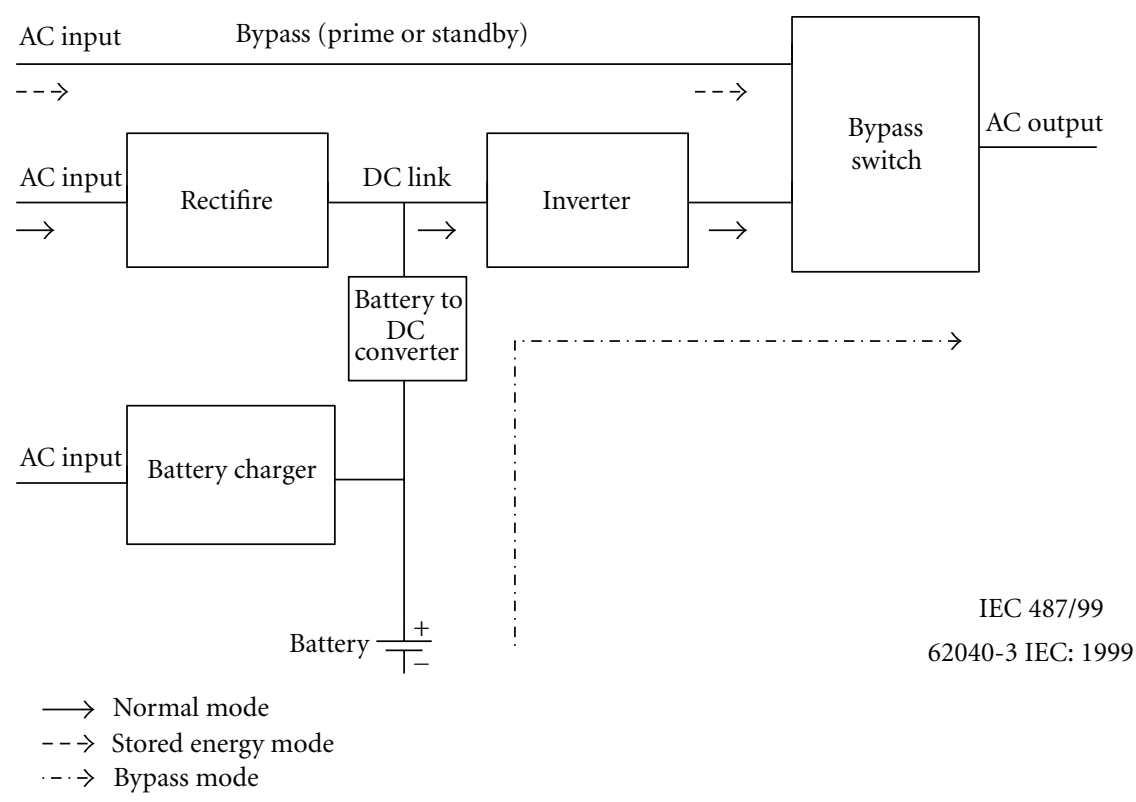

FIGURE 1: Double conversion online UPS based on IEC-62040 standard.

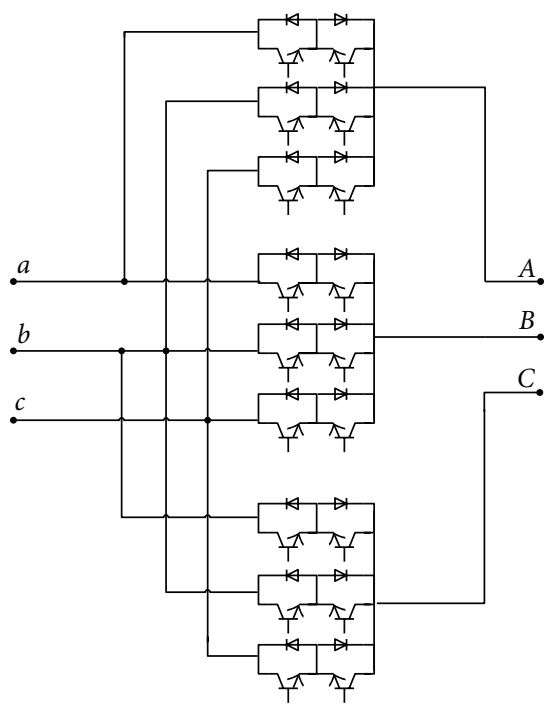

FIgURE 2: Conventional matrix converter.

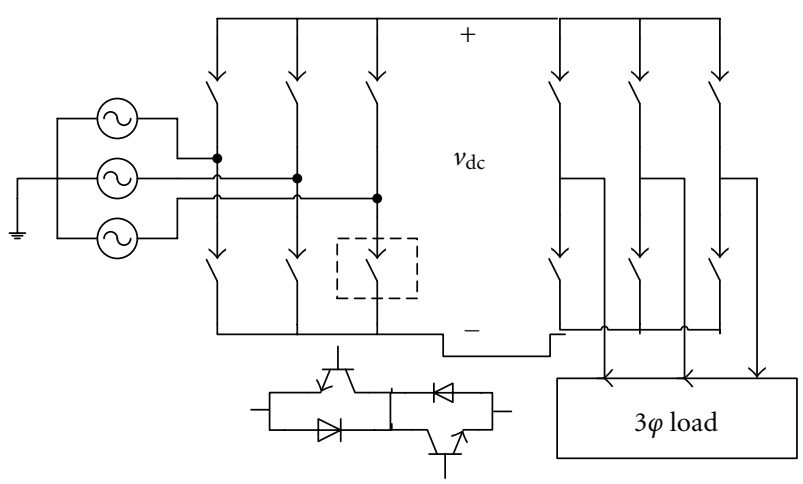

Figure 3: 24-switch topology.
3.1. Conventional Matrix Converter (CMC). CMCs have all the advantages mentioned above and its function, based on Figure 2, can be described as follows.

If the switching function of switches is defined as " 0 " when open and " 1 " when closed, the output voltage is defined by (1) as follows:

$$
\left[\begin{array}{l}
V_{A} \\
V_{B} \\
V_{C}
\end{array}\right]=\left[\begin{array}{lll}
S_{A a} & S_{A b} & S_{A c} \\
S_{B a} & S_{B b} & S_{B c} \\
S_{C a} & S_{C b} & S_{C c}
\end{array}\right] \cdot\left[\begin{array}{c}
V_{a} \\
V_{b} \\
V_{c}
\end{array}\right] .
$$

But there are some drawbacks that stop CMCs from being utilized in industry such as the following:

(i) potential commutation problem,

(ii) complicated control algorithm with the need of high performance microprocessor,

(iii) realization of bidirectional switches,

(iv) elaborate clamp circuit.

As a result, in the past few years the concept of dual bridge matrix converter has developed.

3.2. Dual Bridge Matrix Converter (DBMC). Compared to CMCs, the recently introduced DBMC, Figure 3 , has the following advantages [7].

(i) The difficulty of commutation is reduced. All line side switches turn on and off at zero current and all load side switches commutate similar to a conventional $\mathrm{DC} / \mathrm{AC}$ inverter.

(ii) The number of switches can be reduced under certain constraints.

(iii) The clamp circuit can be greatly simplified, only one capacitor and one diode are used. 
Considering all the advantages that DBMCs offer and the fact that this topology makes the switch reduction possible [7], this topology is chosen and in the next two sections the switch reduction from 24 to 6 is described.

3.3. Steps to Reduce the Switch Number. Reducing the number of switches in DBMC is extensively discussed in the literature such as $[7,12,14]$. In this part, a brief review is presented.

In general 12 bidirectional switches in Figure 3 require 24 unidirectional switches, but by proper assumptions the number of switches can be reduced [7].

In the following part, switch reduction procedure is described in four steps.

Step 1. If, by employing appropriate control technique, the dc-link voltage is set to be positive, then replacing bidirectional switches with unidirectional switches at the load side is possible. This leads to 18-switch topology which is depicted in Figure 4 [7].

Step 2. According to Figure $5[11,14], S_{1}$ and $S_{2}$ can share the same gate signal and can be replaced by one bidirectional switch and two diodes.

So 15 -switch $[10,11]$ topology as shown in Figure 6 can be achieved. This topology is also called "sparse matrix converter" in $[11-13,15]$.

Step 3. By $I_{\mathrm{dc}}>0$ assumption, further switches reduction from 15 to 12 is possible. This leads to 12 -switch topology in Figure 7. This topology is a standard 6-switch rectifier and 6-switch inverter connected back to back.

Step 4. As far as switches $S_{j p}$ and $S_{j n}(j \in a, b, c)$ in Figure 6 are not conducting current and only $S_{a}, S_{b}$, and $S_{c}$ are conducting, the 9-switch topology (also named "ultra sparse matrix converter $[11-13,15]$ ") is obtained and depicted in Figure 8.

By reducing the number of switches to 9 , the presented topology has lost some of its desired features compared to standard and 24-switch topology, like bidirectional power flow between source and load. In 9-switch topology power only flows from source to load and power factor should always be higher than 0.866 .

\section{Proposed Topology}

So far the 9-switch topology is obtained. In this section, we intend to further reduce the switch count by applying the concept of sharing leg between rectification and inversion stages [13-16]. Rectifier with capacitor dc-link is considered as one of the most promising structures for three-phase to three-phase power conversion [14].

In order to achieve this, a leg consists of two series capacitors is added and placed in parallel with rectification stage. The midpoint, tagged by " 0 " in Figure 9, is shared between an input leg and an output leg and results in elimination of

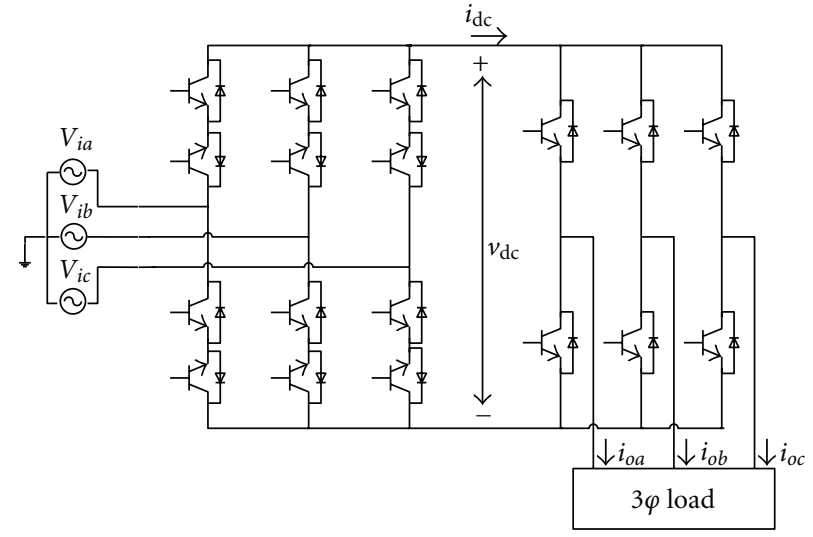

FIGURE 4: 18-switch topology.
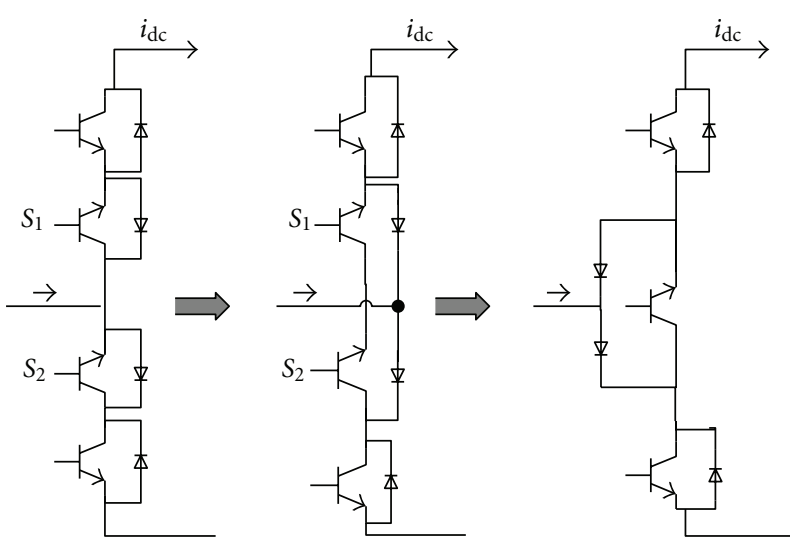

FIgURe 5: Switch reduction procedure as described in Step 2.

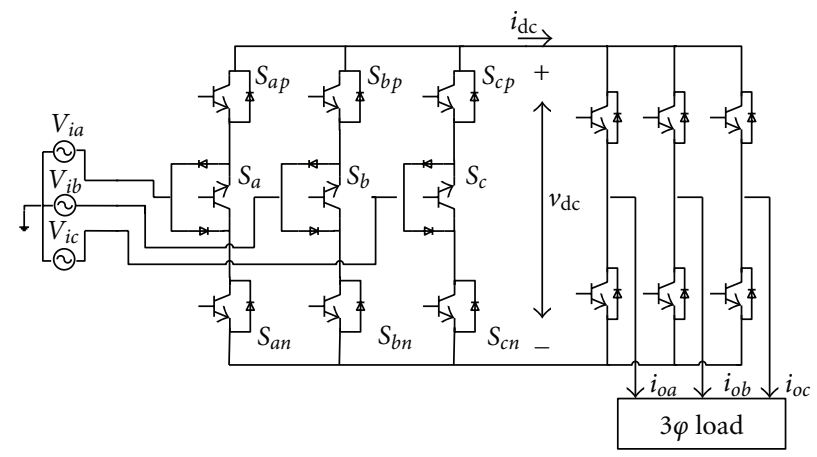

Figure 6: 15-switch topology.

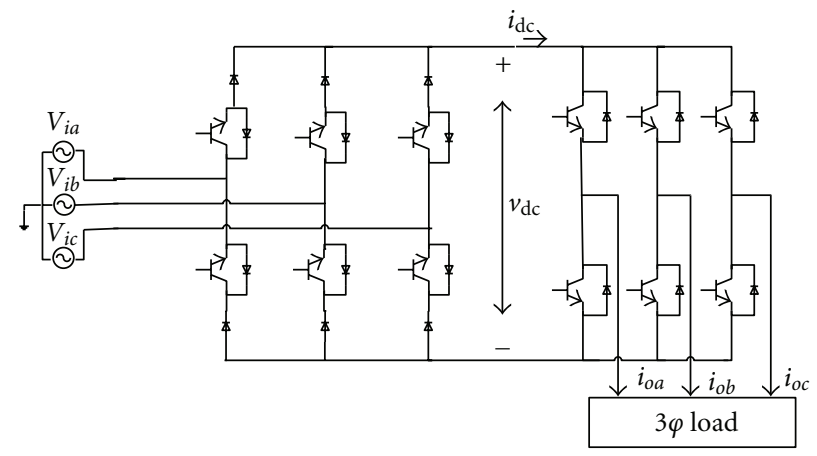

FIGURE 7: 12-switch topology. 


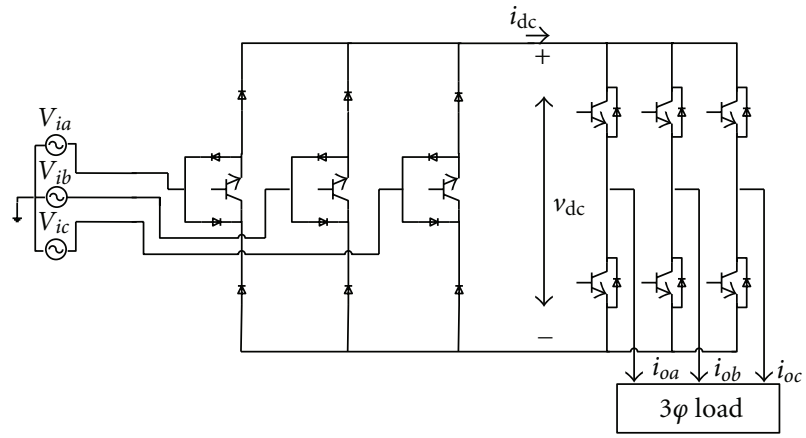

FIGURE 8: 9-switch topology according to [10, 13].

one active switch and four diodes in rectification stage and two active switches in inversion stage.

By replacing the proposed 6-switches converter with rectifier block and inverter block in Figure 1, the novel 6switches UPS is achieved which fulfill desired characteristics of double conversion UPS, such as compactness, output voltage regulation, and controllable frequency.

Three different operation mode of proposed UPS system are as follows.

(i) In normal mode, double conversion process take place through proposed 6-switches matrix converter.

(ii) In stored-energy mode, the batteries are in parallel with inversion stage and feed the load.

(iii) In by-pass mode, the by-pass switch in Figure 9 is closed and load is directly connected to the source.

Reliability is considered one of the most important characteristics of UPS system. It is indicated in the literature that $92 \%$ of all UPS failures are related to battery malfunction. This happens because of electrochemical nature of batteries. So providing the best operating condition for battery bank is of high importance when designing UPS system [1]. Since we can tightly regulate dc-link voltage in presented topology, the battery bank, which is consist of two set of batteries, is directly connected to the split capacitor dc bus.

By applying appropriate control technique, achieving sinusoidal output waveforms and controlled dc-link voltage is possible.

The control circuit in rectification stage consists of multiple control lops for each switches, one outer voltage loop and one inner current loop [1]. The first loop takes dc-link capacitor voltage as a feedback signal and compares it with reference voltage, which calculates error signal and by processing that signal, reference signal for second loop can be created. In second loop input current is sampled and compared with generated reference in first loop and PWM waveform with $30 \mathrm{kHz}$ switching frequency is created and applied to active switches.

The 4 switches output inverter is controlled in a high frequency PWM pattern in order to produce high quality output voltage. Reference voltages for each of two legs are 120 degree shifted from each other. So produced line voltages are 120 degree shifted. As a result, the line voltage shared leg is
TABLE 1: System parameters.

\begin{tabular}{lc}
\hline Parameters & Rating \\
\hline Power & $1.2 \mathrm{kw}$ \\
Input voltage (line-line) & $420 \mathrm{v}$ \\
Input filter & $L=20 \mathrm{uh}, C=200 \mathrm{uf}$ \\
Power factor & 0.94 \\
Output voltage (line-line) & $300 \mathrm{v}$ \\
Output filter & $L=15 \mathrm{uh}, C=10 \mathrm{uf}$ \\
THD & $3.2 \%$ \\
Efficiency & $89 \%$ \\
Load & $L=10 \mathrm{mh}, R=40 \Omega$ \\
DC-Link voltage & $650-700 \mathrm{v}$ \\
\hline
\end{tabular}

also 120 degree shifted which completes symmetrical system of line voltages.

The control technique for output converter uses two control loops for each leg, one outer voltage loop and one inner current loop. As mentioned above, two reference voltages for each leg are 120 degree shifted from each other. Output voltage is sampled to calculate the error signal. For achieving stable voltage during steady state operation, PID module is used.

Calculated voltage error is also used as a reference signal for current loop. This loop uses the output line current as feedback signal. This loop is faster and is used to improve the dynamic response of the output converter.

In the next section, simulation result of the proposed UPS system is provided. Using the aforementioned control strategee will guaranty the performance of the system. In the rated power, during the steady state operation, as simulation results demonstrate, THD is lower than $3.2 \%$, efficiency is about $89 \%$, and sinusoidal output voltage and current for different load conditions are achieved.

\section{Simulation Results}

Simulation is carried out by using PSIM software. In the simulation, all switches are considered ideal. The voltage and current waveforms of the input, dc-link voltage as well as load current and voltage are depicted in this part to demonstrate the performance of proposed 6-switch topology (Figure 9) and applied control technique. The system parameters of simulated circuit are given in Table 1.

Figure 10 shows the simulation result for input current. In Figure 11, voltage and current phase "a" are shown. According to simulation result, power factor in input stage is 0.94 .

Simulation result for dc-link voltage and current is shown in Figures 12 and 13.

DC-Link voltage is controlled using hysteresis controller. As shown in Figure 12, the voltage is fairly fitted between two set values.

Dc current is always positive which satisfies Step 3 in switch reduction procedure. 


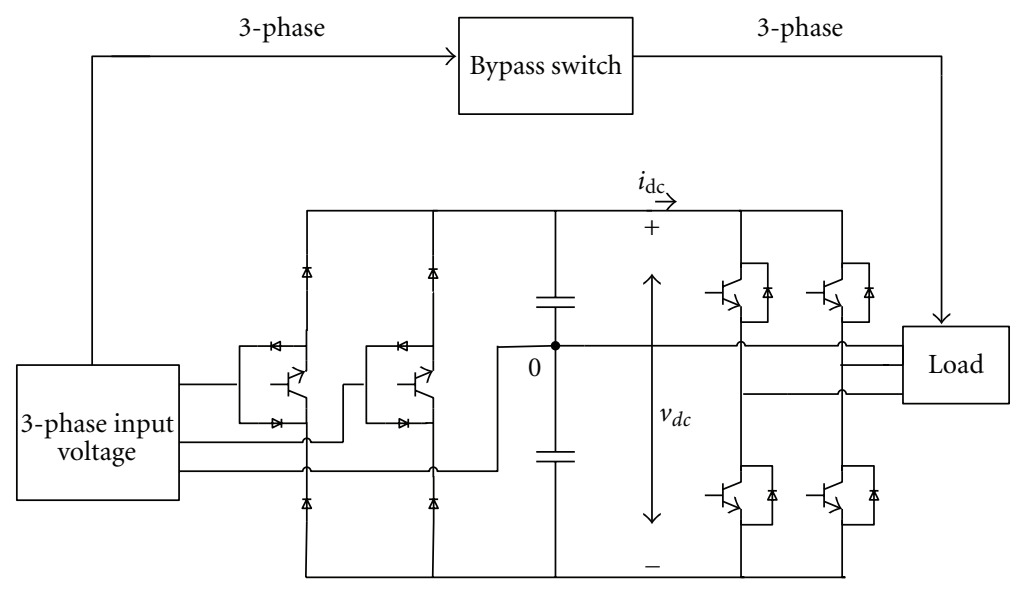

Figure 9: Proposed 6-switch topology.

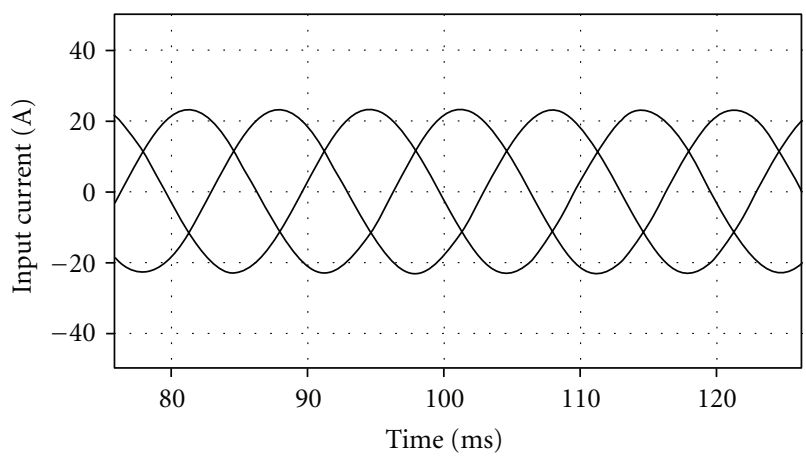

FIGURE 10: Input current of the 6-switch topology.

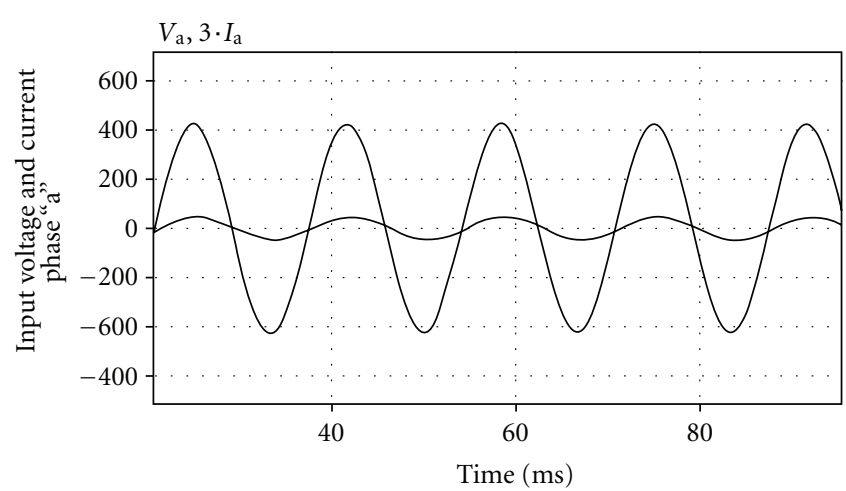

FIGURE 11: Input voltage and current of the 6-switch topology, Phase "a."

Figure 14 shows the output current for three-phase load connected to the back-end inverter. The applied current controller shows acceptable performance to supply load with three-phase sinusoidal current.

In Figure 15, the output voltage is shown. In order to demonstrate output voltage, a low pass filter is used and the cutoff frequency is set to $1000 \mathrm{~Hz}$.

Demonstration of output voltage and current of phase "a" is presented in Figure 16. In this figure, the performance

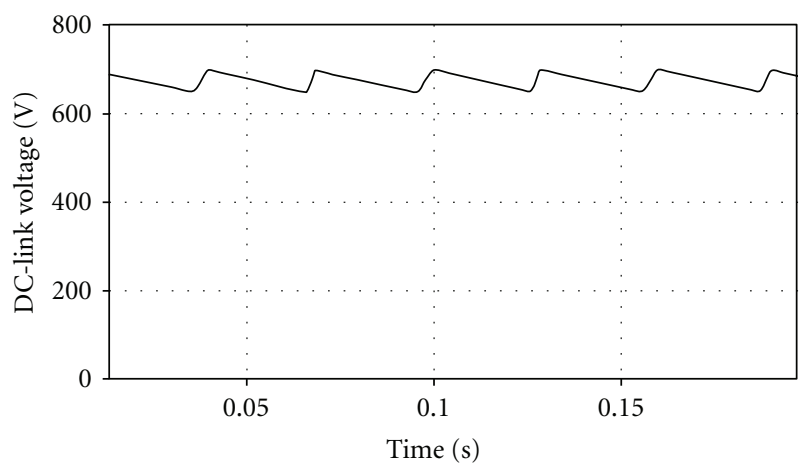

FIGURE 12: DC-link voltage of the 6-switch topology.

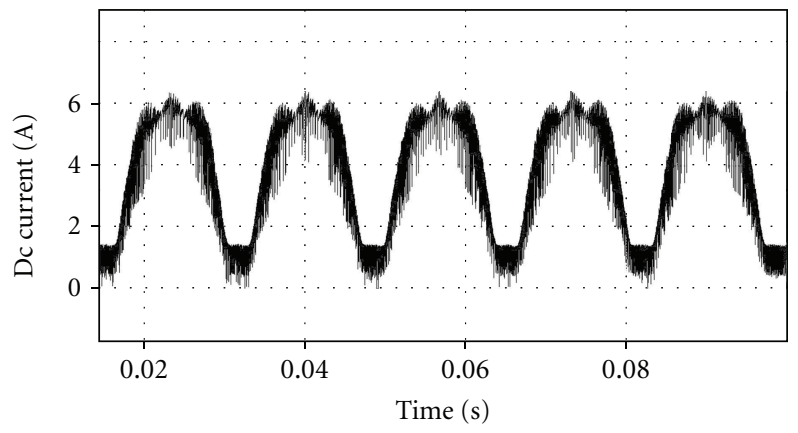

FIGURE 13: DC current of the 6-switch topology.

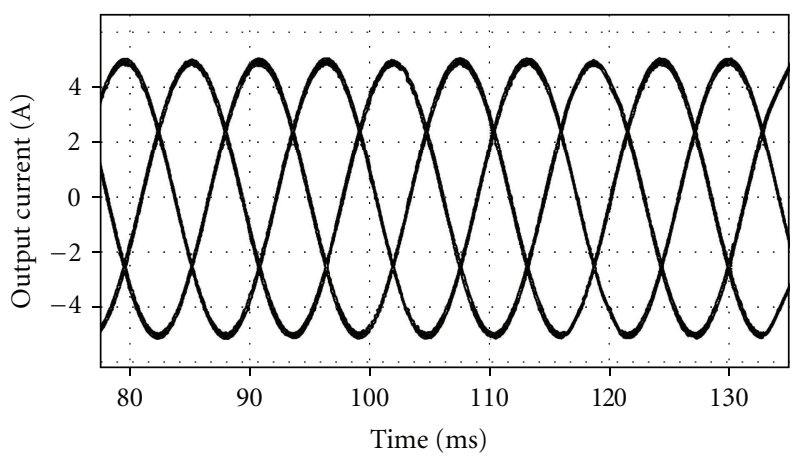

Figure 14: Output current of the 6-switches topology. 


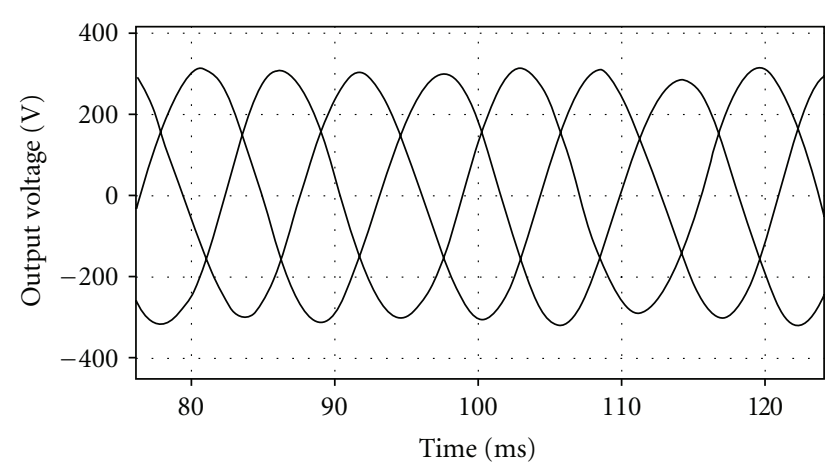

FIGURE 15: Output voltage of the 6-switch topology.

(c)

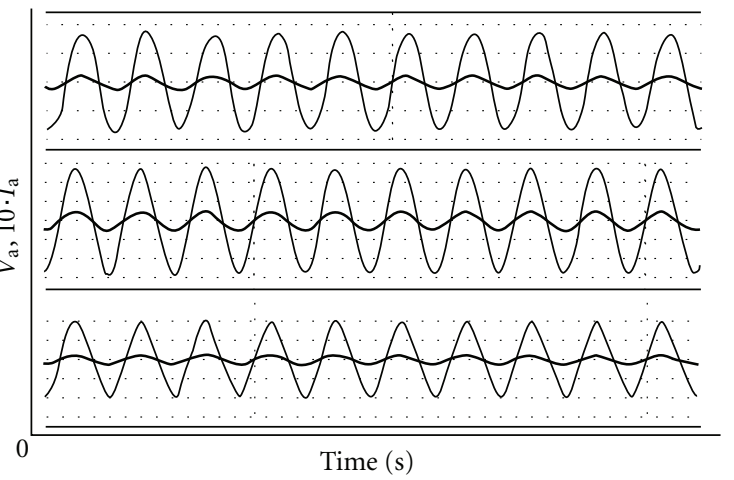

Figure 16: Output voltage and current at different load conditions (a) resistive load (b) 50\% of rated Load (c) $120 \%$ rated load.

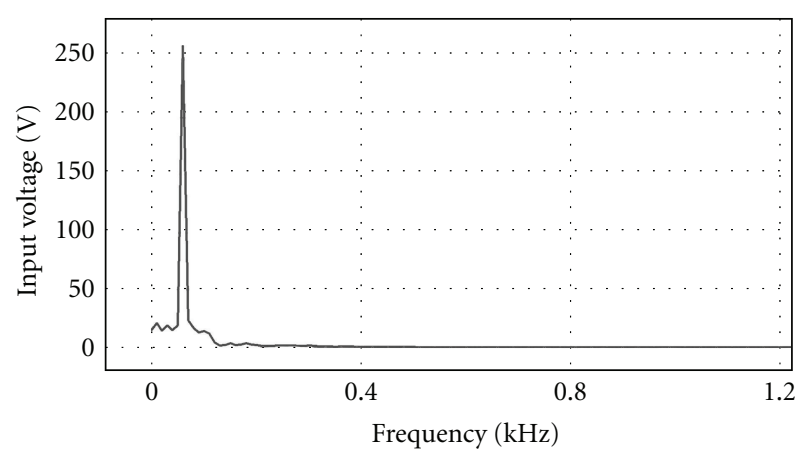

Figure 17: Output voltage of the 6-switch topology in frequency domain.

of the system for three different load conditions is shown, from resistive load to $120 \%$ of rated load. In this range, the proposed UPS system demonstrates a good performance in achieving sinusoidal waveforms and high power factor.

Figure 17 demonstrates output voltage in frequency domain. For calculating total harmonic distortion, the THD box in PSIM software is used. In steady state operation, THD is equal to $3.2 \%$.

\section{Conclusions}

The performance of proposed 6-switch online UPS is investigated in this paper. Applied topology is based on the reduced switch count dual bridge matrix converter. Reducing the number of power switches leads to low price, highly reliable, and compact design. The proposed topology shows excellent performance, produced high quality, sinusoidal output voltage, and current waveforms. Simulation results have been presented to confirm the advantages of the proposed novel UPS system.

\section{References}

[1] A. Emadi, A. Nasiri, and S. B. Bekiarov, Uninterruptible Power Supplies and Active Filters, CRC Press, 2005.

[2] H. R. Karshenas and M. Niroomand, "Design and implementation of a single phase inverter with sine wave tracking method for emergency power supply with high performance reference," in Proceedings of the 8th International Conference on Electrical Machines and Systems (ICEMS '05), pp. 1232-1237, September 2005.

[3] M. Niroomand and H. R. Karshenas, "Hybrid learning control strategy for three-phase uninterruptible power supply," IET Power Electronics, vol. 4, no. 7, pp. 799-807, 2011.

[4] M. Niroomand and H. R. Karshenas, "Design and implementation of a new hybrid learning control strategy for threephase UPS," in Proceedings of the 11th International Conference on Electrical Machines and Systems (ICEMS ;08), pp. 17321737, October 2008.

[5] A. Nasiri, S. B. Bekiarov, and A. Emadi, "Reduced parts threephase series-parallel UPS system with active filter capabilities," in Proceedings of the 38th IAS Annual Meeting, IEEE Industry Applications Conference, vol. 2, pp. 963-969, October 2003.

[6] M. Niroomand and H. R. Karshenas, "Review and comparison of control methods for uninterruptible power supplies," in Proceedings of the Power Electronic \& Drive Systems \& Technologies Conference (PEDSTC '10), pp. 18-23, IEEE, 2010.

[7] A. Nasiri, "Digital control of three-phase series-parallel uninterruptible power supply systems," IEEE Transactions on Power Electronics, vol. 22, no. 4, pp. 1116-1127, 2007.

[8] H. R. Karshenas and M. Niroomand, "Analysis and comparison of two control strategies for three-phase series-parallel UPS," in Proceedings of the 11th International Conference on Electrical Machines and Systems (ICEMS '08), pp. 1726-1731, October 2008.

[9] J. Holtz and U. Boelkens, "Direct frequency converter with sinusoidal line currents for speed-variable AC motors," IEEE Transactions on Industrial Electronics, vol. 36, no. 4, pp. 475479, 1989.

[10] L. Wei and T. A. Lipo, "A novel matrix converter topology with simple commutation," in Proceedings of the 36th IAS Annual Meeting, pp. 1749-1754, October 2001.

[11] J. W. Kolar, M. Baumann, F. Schafmeister, and H. Ertl, "Novel three-phase AC-DC-AC sparse matrix converter," in Proceedings of the 17th Annual IEEE Applied Power Electronics Conference and Expositions, pp. 777-791, Dallas, Tex, USA, March 2002.

[12] P. W. Wheeler, J. Rodríguez, J. C. Clare, L. Empringham, and A. Weinstein, "Matrix converters: a technology review," IEEE Transactions on Industrial Electronics, vol. 49, no. 2, pp. 276288, 2002. 
[13] J. W. Kolar, F. Schafmeister, S. D. Round, and H. Ertl, "Novel three-Phase AC-AC sparse matrix converters," IEEE Transactions on Power Electronics, vol. 22, no. 5, pp. 1649-1661, 2007.

[14] L. Wei, T. A. Lipo, and H. Chan, "Matrix converter topologies with reduced number of switches," in Proceedings of the IEEE 33rd Annual Power Electronics Specialists Conference (PESC '02), pp. 57-63, June 2002.

[15] C. Klumpner, M. Lee, C. Pitic, P. Wheeler, and P. Zanchetta, "A new three-level indirect matrix converter with reduced number of switches," in Proceedings of the IEEE Industry Applications Conference 42nd Annual Meeting, pp. 186-193, September 2007.

[16] L. Wei, T. A. Lipo, and H. Chan, "Robust voltage commutation of the conventional matrix converter," in Proceedings of the IEEE 34th Annual Power Electronics Specialists Conference, pp. 717-722, June 2003. 

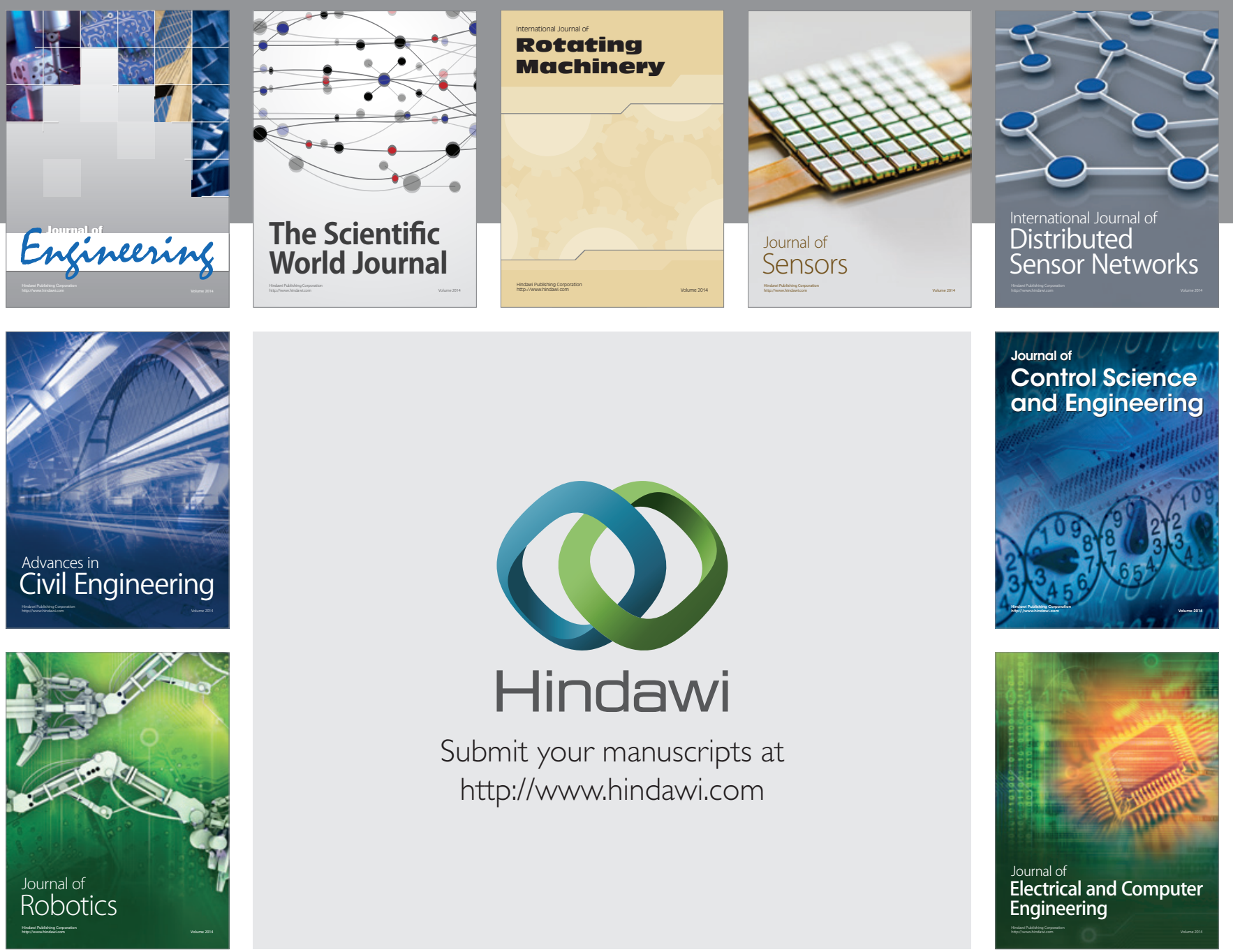

Submit your manuscripts at

http://www.hindawi.com
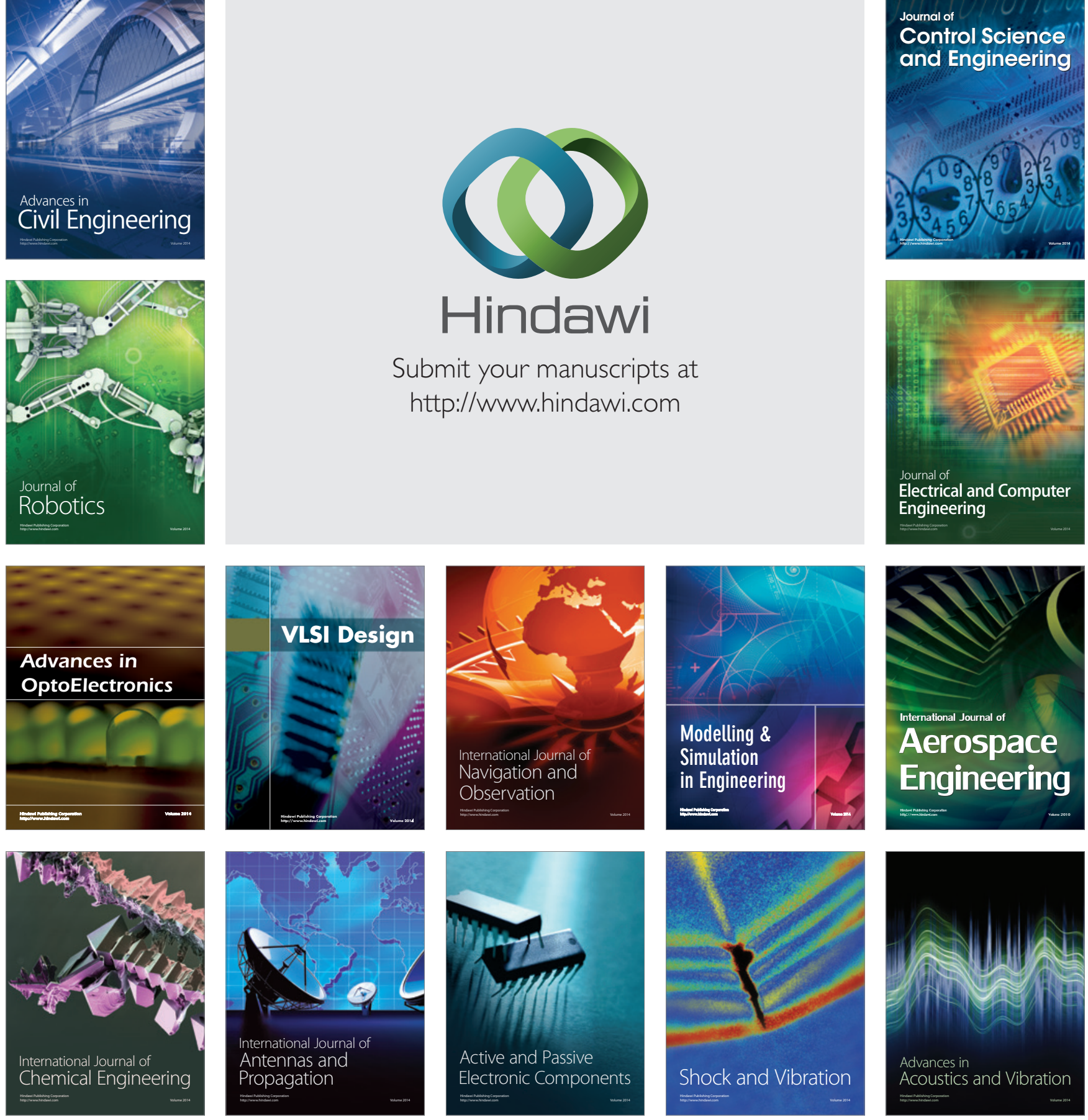